\title{
Changing prevalence of Helicobacter pylori infection in children and adolescents
}

\author{
Ji Sook Park, MD ${ }^{1,2}$, Jin Su Jun, PhD ${ }^{1,2}$, Ji-Hyun Seo, MD ${ }^{1,2}$, Hee-Shang Youn, MD ${ }^{1,2}$, Kwang-Ho Rhee, MD ${ }^{2,3}$ \\ ${ }^{1}$ Department of Pediatrics, Gyeongsang National University Hospital, Gyeongsang National University College of Medicine, Jinju, Korea; ${ }^{2}$ Institute of Health Sciences, \\ Gyeongsang National University, Jinju, Korea; ${ }^{3}$ Department of Microbiology, Gyeongsang National University College of Medicine, Jinju, Korea
}

Helicobacter pylori infection has declined over recent decades. However, its prevalence remains high, and nearly $50 \%$ of the global population has been infected. In Korea, seroprevalence has steadily decreased in adults, but the status of $H$. pylori infection in children is unknown. The current status or trend of $H$. pylori infection in children is important because it can help estimate H. pylori-related diseases including gastric cancer in later life. In this review, the authors discuss the change in $H$. pylori infection rate among children and adolescents based on literature reviews and our research.

Key words: Helicobacterpylori, Infection, Child, Adolescent

\section{Key message}

Although Helicobacter pylori infection rate in children is unclear due to diversity and limitation of diagnostic tests unlike in adults, investigation the childhood prevalence is important for predicting $H$. pylori-related diseases in the future.

H. pylori infection occurred in early childhood, and declined during 30 years in our study.

Change in risk factors of $H$. pylori transmission and consensus for eradication therapy in children might further reduce the infection rate.

\section{Introduction}

The prevalence of Helicobacter pylori has declined over recent decades due to improved sanitation, socioeconomic development, and better living conditions; however, its prevalence remains high in the developing world. ${ }^{1)} H$. pylori has infected nearly $50 \%$ of the population worldwide, with rates of $35 \%-$ $90 \%$ depending on population diversity and geographic area. ${ }^{2)}$ In Korea, the seroprevalence in adults has decreased over the past 13 years. ${ }^{3)} H$. pylori infection may occur in infancy or early childhood and generally persists for life if left untreated. ${ }^{2,4-6)}$ Chronic $H$. pylori infection plays a pivotal role in the development of peptic ulcer, atrophic gastritis, and gastric cancer. ${ }^{7)}$
The $H$. pylori infection status in children versus adults is not fully known since most infected children remain asymptomatic and studies are limited. The diagnostic diversity of $H$. pylori can contribute to variable infection rates in children. ${ }^{8)}$ It is important to investigate the current $H$. pylori infection rate in children because it can be helpful for predicting the future incidence of $H$. pylori-related gastric diseases. This review examines the trend of H. pylori infection and risk factors associated with its transmission in children and adolescents based on a literature review and our own research.

\section{Prevalence of $H$. pylori infection during childhood and adolescence in Korea}

The H. pylori infection rate of symptomatic children has been steadily decreasing over the past 30 years in Korea. ${ }^{9-11)}$ Lee et al. ${ }^{9)}$ reported a decrease in the prevalence of $H$. pylori infection in children aged 2-15 years with recurrent abdominal pain from 25.1\% to $10.8 \%$ between 1991 and 2008 in Seoul, and the infection status was determined using rapid urease tests (RUTs; commercial CLO test).

In the Kyungpook area, the $H$. pylori infection rate of children aged 4-16 years with recurrent abdominal pain was 7.4\%; the rate did not decrease significantly from 2004 to 2014. H. pylori infection was determined by urea breath testing (UBT) in that study. ${ }^{11)}$ Jang et al. ${ }^{11)}$ found that the infection rate of children younger than 12 years was less than $(6.5 \%)$ that of children aged $\geq 12$ years (9.2\%). Despite differences in investigation timing, region, and diagnostic method, the overall $H$. pylori infection rate appeared to decrease from 1991 to 2014 in symptomatic children in Korea. ${ }^{9,11)}$

Malaty et al. ${ }^{10)}$ reported that the infection rate in asymptomatic Korean children was $22 \%$ based on an enzyme-linked immunosorbent assay (ELISA) for anti-H. pylori immunoglobulin $\mathrm{G}(\mathrm{IgG})$ in 1996. The authors compared the infection rates of children aged 1-19 years with those of adults aged $20-75$ years and found a lower prevalence in the former (22\% vs. $75 \%)$.

Corresponding author: Hee-Shang Youn, MD, PhD. Department of Pediatrics, Gyeongsang National University Hospital, 15 Jinju-daero $816 b e o n-g i l$, Jinju 52727, Korea 凶E-mail: hsyoun@gnu.ac.kr, https://orcid.org/0000-0002-5498-838X

Received: 10 December, 2019, Accepted: 14 February, 2020

This is an open-access article distributed under the terms of the Creative Commons Attribution Non-Commercial License (http://creativecommons.org/licenses/bync/4.0/) which permits unrestricted non-commercial use, distribution, and reproduction in any medium, provided the original work is properly cited.

Copyright (c) 2021 by The Korean Pediatric Society 
Our research team has been investigating the prevalence of $H$. pylori infection since the late 1980s among asymptomatic children and adolescents using immunoblot analysis for anti- $H$. pylori IgG in western Gyeongnam. In this area, the H. pylori infection rate was relatively high, exceeding $80 \%$ in children older than 7 years of age among an asymptomatic population during the late $1980 \mathrm{~s}^{4)}$ Although the presence of anti-H. pylori IgG cannot be used to distinguish between past and current infection, a positive IgG result in asymptomatic children can reflect $H$. pylori infection status based on the fact that $H$. pylori infection persists unless it is treated. ${ }^{4,5)}$

The overall seroprevalence among asymptomatic pediatric patients ranging from neonates to 19 -year-olds has decreased from $62.2 \%$ in 1988 to $18.2 \%$ in 2015; the age-specific infection rate has also declined. The lowest positive rate was detected in infancy and early childhood between 6 months and 4 years and has declined over the past 30 years (Fig. 1; unpublished data). Based on our investigations, the incidence of $H$. pylori-related diseases will decrease among adults in the future in western Gyeongnam in the absence of new infection after childhood. The infection rate in children did not differ between males and females in our investigation in concordance with previous studies. ${ }^{9,11)}$

A wide range of infection rates was reported in children in previous studies, possibly caused by different living regions, diagnostic methods, ages, and symptoms of the study population. ${ }^{9-11)}$

Our study using a homemade liquid-type RUT in the early 1990s detected $H$. pylori in 49 of 107 symptomatic children aged 2-15 years (46\%). The $H$. pylori infection rate in symptomatic children was higher in the western Gyeongnam than in Seoul $(25.1 \%)$ in the early 1990s. The difference in infection rate might be attributed to differences in the RUT used in the study and in rural versus urban areas where the study subjects resided during that time. The detection rate of $H$. pylori varied by diagnostic method. One of our studies suggested that immunoblot analysis was the most sensitive test among noninvasive tests for $H$. pylori infection in symptomatic children (Table 1 ; unpublished data).

The stool antigen test is a noninvasive test used to detect $H$.

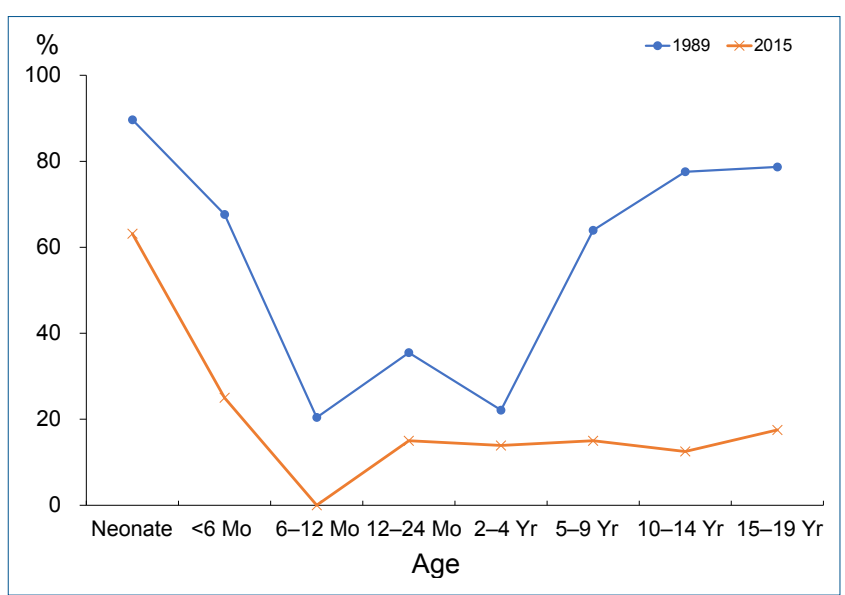

Fig. 1. Changes in Helicobacter pylori immunoglobulin G seropositivity using immunoblot analysis among asymptomatic children and adolescents by age over the past 30 years in western Gyeongnam. pylori infection. However, we did not investigate the diagnostic accuracy of the stool antigen test or compare it to other diagnostic methods. Epidemiologic studies in children using $H$. pylori stool antigen $(\mathrm{HpSA})$ test are rare because $\mathrm{HpSA}$ has high false positive rates in children younger than 6 years and can be affected by stool patency or individual clinical condition. ${ }^{8,12)}$ RUT results also depend on the number of biopsy samples due to the patchy distribution of $H$. pylori in children (Table 2). ${ }^{13)}$

Cross-sectional nationwide multicenter studies in an asymptomatic Korean population aged 16 years and older showed a serial decrease in seroprevalence from $66.9 \%$ to $43.9 \%$ over the past 20 years (1998-2017), with differences in the seroprevalence and decremental degree between urban and rural areas. ${ }^{3,14)}$

The $H$. pylori infection rate varied by age in previous studies including our research and increased with age. ${ }^{9-11)}$ Increasing seroprevalence with age might be attributed to a birth cohort effect. ${ }^{3)}$ However, new infections may also occur throughout life because anti-H. pylori IgM or IgA was positive in all age groups ranging from newborns to adults in our recent research, albeit with low rate (IgM, 5.4\%-9.9\%; IgA, 24.9\%-30.7\%; unpublished data). Seropositivities for $H$. pylori IgG were high in neonates and early infants in our study, which reflected seropositivity in women of childbearing age because IgG could be transmitted from mother to fetus through the placenta (Fig. 1).

Based on previous studies including our investigations, although the infection rates varied by age, diagnostic method, and region, it is clear that $H$. pylori infection has decreased in children and adolescents in South Korea. The declining infection rates may predict a reduced future incidence of $H$. pylori-related diseases in children and adults in South Korea.

Table 1. Positive test results and rates by diagnostic test (unpublished data)

\begin{tabular}{lc}
\hline Variable & No. (\%) \\
\hline Immunoelectron microscopy & $116(97)$ \\
Rapid urease test & $107(89)$ \\
Immunoblotting & $98(82)$ \\
Enzyme-linked immunosorbent assay & $25(21)$ \\
${ }^{13}$ C-Urea breath test & $25(21)$ \\
Total & 120 \\
\hline
\end{tabular}

Table 2. Correlation between urease test results and number of biopsy samples among 255 children who underwent upper gastrointestinal endoscopy

\begin{tabular}{|c|c|c|c|c|}
\hline & \multirow{2}{*}{$\begin{array}{l}\text { Single biopsy } \\
\text { specimen }\end{array}$} & \multicolumn{2}{|c|}{ Three biopsy specimens } & \multirow{2}{*}{$P$ value } \\
\hline & & Negative & Positive & \\
\hline \multirow[t]{2}{*}{ Result } & Negative & 164 & 33 & $<0.001$ \\
\hline & Positive & 6 & 52 & \\
\hline
\end{tabular}

$P$ value was obtained by McNemar test.

Modified from Seo et al. J Korean Med Sci 2014:29:106-9. ${ }^{13)}$

Boldface indicates a statistically significant difference with $P<0.05$. 


\section{Prevalence of $H$. pylori infection during childhood and adolescence worldwide}

Although the H. pylori infection rate has decreased in South Korea and developed countries, an estimated overall 33\% of asymptomatic or healthy children were still infected serologically in the world. ${ }^{2)}$ In developed countries such as Japan, ${ }^{15)}$ Germany, ${ }^{16)}$ the Netherlands, ${ }^{17)}$ and the USA, ${ }^{18)}$ relatively lower seroprevalences of $7.7 \%, 11.8 \%, 9.8 \%$, and $5.7 \%$ were reported, respectively. However, high infection rates of $27.2 \%, 65.9 \%$, $25.8 \%$, and $40.4 \%$ were reported in Chile, ${ }^{19)}$ Venezuela, ${ }^{20)}$ Iran, ${ }^{21)}$ and Nigeria, ${ }^{22)}$ respectively.

Similar to reports of Korean epidemiologic studies, the infection rate increased with age. In cohort studies of children under 5 years of age using $\mathrm{HpSA}$, the infection rate was $20 \%$ in Portugal ${ }^{23)}$ and $27.2 \%$ in Chile. ${ }^{19)}$ However, the infection rate was $42 \%$ in Portugal ${ }^{23)}$ and $77.3 \%$ in Chile $^{19)}$ in studies of children older than 5 years of age using HpSA or UBT. Detection rates using UBT or HpSA in symptomatic children were $42.9 \%$ in Chile, ${ }^{24)} 73.9 \%$ in Poland, ${ }^{25)} 10.9 \%$ in the Netherlands, ${ }^{26}$ and $3.2 \%$ in the USA. ${ }^{27)}$

Among symptomatic children, prevalence estimates of $H$. pylori infection vary considerably, 3\%-76\% among countries and diagnostic methods, and the overall worldwide estimate was 39\%.2) The H. pylori detection rates in symptomatic children were generally slightly higher than those in asymptomatic children (around $40 \%$ vs. 33\%).

Our team compared the seroprevalence of $H$. pylori infection among asymptomatic populations in Jinju, Korea, with those of Fukuoka, Japan. The seropositive rate of Fukuoka in the early 1990 s $(20 \%-40 \%)$ was lower than that of Jinju, Korea, in the late 1980s (50\%-90\%) among children and adolescents under 20 years of age. However, the infection rates in adults $\geq 20$ years of age did not differ between the two cities. A 5-year gap existed between the subjects of the investigation. ${ }^{28)}$

A recent Japanese population-based study in which the infection rate was analyzed using $\mathrm{HpSA}$ and UBT in addition to serology tests showed that the prevalence of $H$. pylori infection in Japanese children was approximately 1.8\% with no further infection occurring during the study period. ${ }^{29)}$ The infection rate was markedly decreased compared to that of our earlier report. ${ }^{28)}$

Recent epidemiologic studies showed the high prevalence of H. pylori infection. Over half of adults worldwide were infected with $H$. pylori. ${ }^{1)} H$. pylori appeared to be less common in children than in adults, particularly in children of northern Europe, North America, and Japan. Conversely, it appeared to be more common in children of South America and Asia, including Korea. However, the lower prevalence among younger generations worldwide might suggest a further decline in the prevalence of $H$. pylori infection and associated diseases during the coming decades.

\section{Changes in risk factors for $H$. pylori transmission}

H. pylori transmission modes remain unclear. ${ }^{1)}$ Considering the differences in infection rates between developed and developing countries and between urban and rural areas in South Korea, socioeconomic factors appear to contribute to $H$. pylori transmission. ${ }^{1-3,9,11,28)}$

Due to improved economic, sanitary, and housing conditions, the overall infection rate has declined in South Korea over the past 20 years. ${ }^{9)}$ In previous studies, low income and a rural residence were the risk factors for $H$. pylori infection in South Korea. ${ }^{3,9)}$ An inverse association between educational level and H. pylori carrying status was also reported. ${ }^{30,31)}$

Transmission from person to person has been considered the main route. ${ }^{32}$ According to recent Japanese studies, a significant correlation in infection status between parents and siblings sug. gested intrafamilial transmission of $H$. pylori infection. Parentto-child or grandparent-to-child transmission appeared to be an important route for the spread of $H$. pylori infection. ${ }^{15,29)}$ Thirty-three $H$. pylori isolates obtained from 11 members of three families showed familial clustering of identical random amplified polymorphic DNA fingerprinting types, which might be supportive evidence of person-to-person transmission among closely related individuals such as family members. ${ }^{6,33)}$ Many epidemiologic studies involving children showed that $H$. pylori infection occurred in early childhood and that the infection rate increased at around 5-7 years of age. ${ }^{2,28)}$ During these ages, children usually start to experience group life, for example, kindergarten or elementary school, which may support the possibility of person-to-person transmission.

\section{Conclusion}

Age and sex are not significantly associated with $H$. pylori infection in children and adults. ${ }^{9,11,28,34,35)}$ Although the infection rate increased with age in previous studies, the age-specific gradient in the prevalence of $H$. pylori infection appeared to be related with a birth cohort effect. ${ }^{3,28,34,35)}$

H. pylori infection may occur in early childhood and the probability of persistence is high unless it is eradicated. ${ }^{4,5} \mathrm{~A}$ crosssectional nationwide multicenter study in Korea showed that the H. pylori eradication therapy rate increased and the seropositive rate among adults declined inversely during the previous 18 years. ${ }^{14)}$ The low recurrence rate after successful eradication suggested that the increased rate of eradication therapy may be a minor contributing factor for the decreased prevalence of $H$. pylori in adults. ${ }^{36,37)}$

Despite the lack of agreement of $H$. pylori eradication and indications for therapy in children in $\mathrm{Korea}^{38)}$, consensus regarding the optimal anti-H. pylori management strategy may contribute to further reductions in infection rate among children. 


\section{Conflicts of interest}

No potential conflict of interest relevant to this article was reported.

\section{Acknowledgments}

This study was supported by the Basic Science Research Program through the National Research Foundation of Korea (NRF) funded by the Ministry of Education (NRF-2013R1A1 A2057513). The authors declare no conflicts of interest.

\section{References}

1. Eusebi LH, Zagari RM, Bazzoli F. Epidemiology of Helicobacter pylori infection. Helicobacter 2014;19 Suppl 1:1-5.

2. Zabala Torrres B, Lucero Y, Lagomarcino AJ, Orellana-Manzano A, George S, Torres JP, et al. Review: prevalence and dynamics of Helicobacter pylori infection during childhood. Helicobacter. 2017;22.

3. Lim SH, Kwon JW, Kim N, Kim GH, Kang JM, Park MJ, et al. Prevalence and risk factors of Helicobacter pylori infection in Korea: nationwide multicenter study over 13 years. BMC Gastroenterol 2013;13:104.

4. Rhee KH, Youn HS, Baik SC, Lee WK, Cho MJ, Choi HJ, et al. Prevalence of Helicobacter pylori infection in Korea. J Korean Soc Microbiol 1990;25:475-90.

5. O'Ryan ML, Rabello M, Cortés H, Lucero Y, Peña A, Torres JP. Dynamics of Helicobacter pylori detection in stools during the first 5 years of life in Chile, a rapidly developing country. Pediatr Infect Dis J 2013;32:99-103.

6. Seo JH, Youn JH, Kim EA, Jun JS, Park JS, Yeom JS, et al. Helicobacter pylori antigens inducing early immune response in infants. J Korean Med Sci 2017;32:1139-46.

7. Correa P, Piazuelo MB. Natural history of Helicobacter pylori infection. Dig Liver Dis 2008;40:490-6.

8. Seo JH, Park JS, Rhee KH, Youn HS. Diagnosis of Helicobacter pylori infection in children and adolescents in Korea. Pediatr Gastroenterol Hepatol Nutr 2018;21:219-33.

9. Lee SY, Ko JS, Seo JK. Changes in the prevalence of biopsy-proven Helicobacter pylori infection in Korean children with functional recurrent abdominal pain over the last 18 years. Korean J Pediatr Gastroenterol Nutr 2009;12:150-5.

10. Malaty HM, Kim JG, Kim SD, Graham DY. Prevalence of Helicobacter pylori infection in Korean children: inverse relation to socioeconomic status despite a uniformly high prevalence in adults. Am J Epidemiol 1996;143:257-62.

11. Jang KM, Choe BH, Choe JY, Hong SJ, Park HJ, Chu MA, et al. Changing prevalence of helicobacter pylori infections in Korean children with recurrent abdominal pain. Pediatr Gastroenterol Hepatol Nutr 2015; 18:10-6.

12. Yang HR. Updates on the diagnosis of Helicobacter pylori infection in children: what are the differences between adults and children? Pediatr Gastroenterol Hepatol Nutr 2016;19:96-103.

13. Seo JH, Park JS, Yeom JS, Lim JY, Park CH, Woo HO, et al. Correlation between positive rate and number of biopsy samples on urease test in childhood Helicobacter pylori infection. J Korean Med Sci 2014;29:1069 .

14. Lim SH, Kim N, Kwon JW, Kim SE, Baik GH, Lee JY, et al. Trends in the seroprevalence of Helicobacter pylori infection and its putative eradication rate over 18 years in Korea: a cross-sectional nationwide multicenter study. PLoS One 2018;13:e0204762.

15. Urita Y, Watanabe T, Kawagoe N, Takemoto I, Tanaka H, Kijima S, et al. Role of infected grandmothers in transmission of Helicobacter pylori to children in a Japanese rural town. J Paediatr Child Health 2013;49:3948 .

16. Michel A, Pawlita M, Boeing H, Gissmann L, Waterboer T. Helicobacter pylori antibody patterns in Germany: a cross-sectional population study.
Gut Pathog 2014;6:10.

17. den Hollander WJ, Holster IL, van Gilst B, van Vuuren AJ, Jaddoe VW, Hofman A, et al. Intergenerational reduction in Helicobacter pylori prevalence is similar between different ethnic groups living in a Western city. Gut 2015;64:1200-8.

18. Patterson T, Straten E, Jimenez S. The prevalence of Helicobacter pylori antibody in different age groups in Central Texas. Clin Lab Sci 2012; 25:102-6.

19. Muhsen K, Lagos R, Reymann MK, Graham DY, Pasetti MF, Levine MM. Age-dependent association among Helicobacter pylori infection, serum pepsinogen levels and immune response of children to live oral cholera vaccine CVD 103-HgR. PLoS One 2014;9:e83999.

20. Fuenmayor-Boscán AD, Hernández IM, Valero KJ, Paz AM, Sandrea LB, Rivero Z. Association between Helicobacter pylori and intestinal parasites in an Añu indigenous community of Venezuela. Indian J Gastroenterol 2016;35:106-12.

21. Ghasemi-Kebria F, Ghaemi E, Azadfar S, Roshandel G. Epidemiology of Helicobacter pylori infection among Iranian children. Arab J Gastroenterol 2013;14:169-72.

22. Senbanjo IO, Oshikoya KA, Njokanma OF. Helicobacter pylori associated with breastfeeding, nutritional status and recurrent abdominal pain in healthy Nigerian children. J Infect Dev Ctries 2014;8:448-53.

23. Oleastro M, Pelerito A, Nogueira P, Benoliel J, Santos A, Cabral J, et al. Prevalence and incidence of Helicobacter pylori Infection in a healthy pediatric population in the Lisbon area. Helicobacter 2011;16:363-72.

24. Serrano CA, Talesnik E, Peña A, Rollán A, Duarte I, Torres J, et al. Inverse correlation between allergy markers and Helicobacter pylori infection in children is associated with elevated levels of TGF- $\beta$. Eur J Gastroenterol Hepatol 2011;23:656-63.

25. Parzecka M, Szaflarska-Popławska A, Gasiorowska J, Gorzkiewicz M, Grzybowski T. The prevalence of dupA (duodenal ulcer-promoting gene) of Helicobacter pylori in children and adolescents: own observation. Pol Merkur Lekarski 2013;34:277-80.

26. Gijsbers CF, Benninga M, Büller H. Clinical and laboratory findings in 220 children with recurrent abdominal pain. Acta Paediatr 2011;100:102832.

27. Elitsur Y, Alrazzak BA, Preston D, Demetieva Y. Does Helicobacter pylori protect against eosinophilic esophagitis in children? Helicobacter 2014; 19:367-71.

28. Youn HS, Baik SC, Cho YK, Woo HO, Ahn YO, Kim K, et al. Comparison of Helicobacter pylori infection between Fukuoka, Japan and Chinju, Korea. Helicobacter 1998;3:9-14.

29. Okuda M, Osaki T, Lin Y, Yonezawa H, Maekawa K, Kamiya S, et al. Low prevalence and incidence of Helicobacter pylori infection in children: a population-based study in Japan. Helicobacter 2015;20:133-8.

30. Den Hollander WJ, Holster IL, den Hoed CM, van Deurzen F, van Vuuren AJ, Jaddoe VW, et al. Ethnicity is a strong predictor for Helicobacter pylori infection in young women in a multi-ethnic European city. J Gastroenterol Hepatol 2013;28:1705-11.

31. Ozaydin N, Turkyilmaz SA, Cali S. Prevalence and risk factors of Helicobacter pylori in Turkey: a nationally-representative, cross-sectional, screening with the ${ }^{13} \mathrm{C}$-Urea breath test. BMC Public Health 2013; 13:1215.

32. Kivi M, Tindberg Y, Sörberg M, Casswall TH, Befrits R, Hellström PM, et al. Concordance of Helicobacter pylori strains within families. J Clin Microbiol 2003;41:5604-8.

33. Cho MJ, Lee WK, Jeon YS, Kim KH, Kim SH, Baik SC, et al. Intrafamilial transmission of Helicobacter pylori detected by random amplified polymorphic DNA fingerprinting. Mol Cells 1995;5:508-13.

34. Benajah DA, Lahbabi M, Alaoui S, El Rhazi K, El Abkari M, Nejjari C, et al. Prevalence of Helicobacter pylori and its recurrence after successful eradication in a developing nation (Morocco). Clin Res Hepatol Gastroenterol 2013;37:519-26.

35. Mathewos B, Moges B, Dagnew M. Seroprevalence and trend of Helicobacter pylori infection in Gondar University Hospital among dyspeptic patients, Gondar, North West Ethiopia. BMC Res Notes 2013; 6:346. 
36. Kim MS, Kim N, Kim SE, Jo HJ, Shin CM, Lee SH, et al. Long-term follow-up Helicobacter pylori reinfection rate and its associated factors in Korea. Helicobacter 2013;18:135-42.

37. Yan TL, Hu QD, Zhang Q, Li YM, Liang TB. National rates of Helicobacter pylori recurrence are significantly and inversely correlated with human development index. Aliment Pharmacol Ther 2013;37:963-8.

38. Jun JS, Seo JH, Park JS, Rhee KH, Youn HS. Changes in the treatment strategies for Helicobacter pylori infection in children and adolescents in Korea. Pediatr Gastroenterol Hepatol Nutr 2019;22:417-30.
How to cite this article: Park JS, Jun JS, Seo JH, Youn HS, Rhee KH. Changing prevalence of Helicobacter pylori infection in children and adolescents. Clin Exp Pediatr 2021;64:21-5. https://doi.org/10.3345/cep.2019.01543 